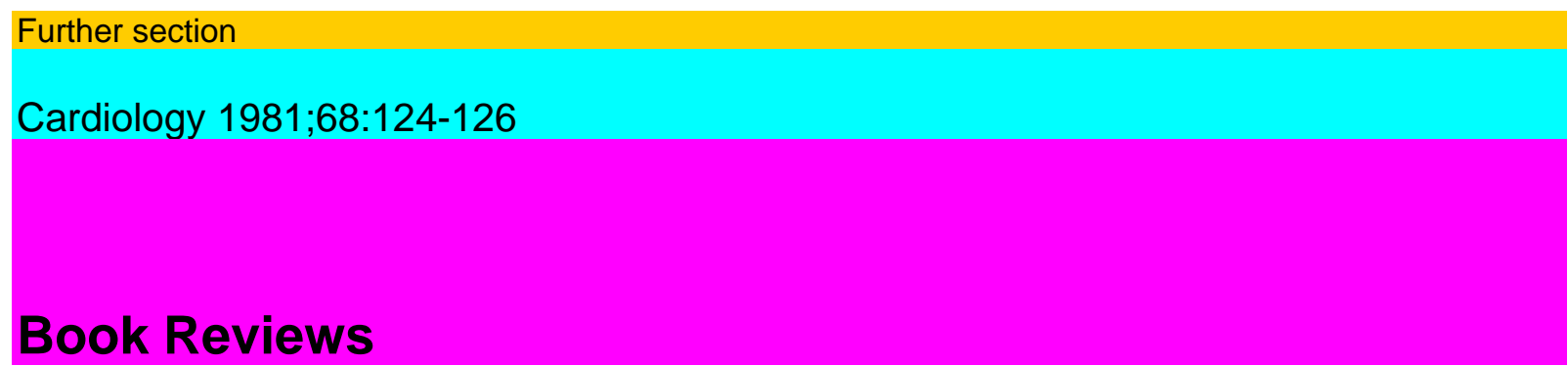

\title{
D.B. Gordon
}

Hypertension: The Renal Basis

Benchmark Papers in Human Physiology, vol. 13 Academic Press, New York 1980 XV + 432 pp.; US \$ 45.00 ISBN 0-87933-356-1

Dr. David B. Gordon, active at the Veterans Administration Hospital in Livermore, Calif, has taken on the difficult task to pick, as seen by his own eyes, the key publications on the role of the kidney in hypertension, and to collect them in one volume. In his preface Gordon states that the volume is a sequel and a follow-up to Arthur Ruskirts book entitled 'Classics in Arterial Hypertension', and accordingly, the Gordon volume logically has in its first part a publication by Harry Goldblatt from 1937. It ends with a paper by Louis Tobian and co-workers from 1978. The difficulties connected with such a selection are quite obvious and as the editor himself states, 'a frank admission is called for that the selection of papers in this collection is a biased one'. Nevertheless, Gordon has succeeded in giving a reliable and reasonably full picture of the evolution in this important field mainly during the last five decades.

However, deficiencies are inevitable, and for the well-oriented reader it is unsatisfying that, for instace, the information about the important work continuously done by Muir-head and coworkers ends with a paper from 1960, disregarding their important papers from recent years. Further, one is left rather uninformed about discoveries and developments outside the Englishspeaking world, although there are a small number of translated publications (unfortunately the originals are not reproduced) from Argentina and Germany, the latest one being from 1957. In spite of such shortcomings the volume gives a good survey of the development in this fascinating field. The editor's summarizing comments in the beginning of each part of the volume efficaciously put the inexperienced reader into the picture, making it possible for him to successively grasp the innovations made, and they also bring him closer up to date than the reprinted articles do.

The volume is recommended to those interested in getting aquainted with the field, and to those who, like myself, for more nostalgic reasons wish to have a competent guide when looking backwards.

Rune Sannerstedt, Goteborg

Book Reviews

125

Shoji Hayase and Satoru Murao Cardiology

International Congress Series 470 Excerpta Medica, Amsterdam 1979 XXIII + 1163 pp.; Dfl. 400.- I US\$ 195.00 ISBN 0-444-90071-3

This volume comprises the scientific sessions of the 8th World Congress of Cardiology held in Tokyo, 17-23 September, 1978.

The contents include lectures and papers presented at 45 symposia.

It is a very impressive review on the state of'Cardiology of the 1980s' represented by leading scientists from all over the world. 
The subjects range from preventive cardiology, new aspects of lipid metabolism and arterosclerosis, protection of the ischemic myocardium, sudden death and the natural history of cardiomyopathies, to exercise cardiology, myocardial metabolism, pathogenesis of hypertension, treatment of cardiac failure and arrhythmias and new aspects of noninvasive techniques. These are only some of the important subjects discussed at the symposia.

This impressive volume reflects the scientific quality of the 8th World Congress, the outstanding organizatory skills of our Japanese colleagues and the special effort invested by the editors who represent the scientific committee of the congress.

We should like to recommend this volume to everyone interested in gaining up-to-date first hand information about the subjects discussed.

J.J. Kellermann

F.L. Abel, E.P. McCutcheon

Cardiovascular Function. Principles and Applications

Little, Brown, Boston 1979 XIX + 424 pp.; US \$ 35.00 ISBN 0-316-00190-2

The Preface states the primary designation of readers of this 420-page monograph -students and fellows. However, it contains information which should be appreciated by all cardiologists engaged in the quantitative definition of cardiovascular function. The efforts of the principal authors are supplemented by four contributors.

The book is appropriately divided into sections on cardiovascular measurements, cardiac function, the vascular system, and circulatory integration and regulation. The material is complete and up-to-date, and gives a comprehensive statement of the physical basis of measurement and the physiological control of cardiac function, the vascular system and integrative relationships. The section on cardiovascular measurements would be strengthened by more clear definitions of the practical aspects of pressure and blood flow measurements in man. In particular, more emphasis should be directed to acceptable

Book Reviews

126

dynamic response levels for the human with 'rationally' damped catheter-manometer systems as defined by Wood. The current frequency of applications of the thermodilution technique for the measurement of cardiac output should likewise be reflected in a more extensive consideration of the practical limitations of this method, and appropriate data on its precision and accuracy. The dilution method could be presented as an extension of fixed principle which might be considered in greater mathematical detail as in the classical paper of Meier and Zierler. Flow and ejection fraction measurements using currently available radioisotopic techniques are not mentioned. This book is highly recommended for the purpose for which it is designed. It provides a modern updated and concise course on the essentials of cardiovascular function. It is to be hoped that subsequent volumes will justify modest revisions with inclusion of specific data obtained from human applications.

H.J.C. Swan, Los Angeles, Calif. 